\title{
Dual action of acertannins as potential regulators of intracellular ceramide levels
}

Akiko Kamori, ${ }^{a}$ Atsushi Kato, ${ }^{\mathrm{a}, *}$ Shota Miyawaki, ${ }^{\mathrm{a}}$ Junna Koyama, ${ }^{\mathrm{a}}$ Robert J. Nash, ${ }^{\mathrm{b}}$ George W. J. Fleet, ${ }^{\mathrm{c}, *}$ Daisuke Miura, ${ }^{\mathrm{d}}$ Fumihiro Ishikawa, ${ }^{\mathrm{d}}$ Isao Adachi, ${ }^{\mathrm{a}}$

Atsushi - I do not need a star for this - how about adding a star to Ishikawa and replalcing my email with his....

a Department of Hospital Pharmacy, University of Toyama, Toyama 930-0194, Japan

${ }^{b}$ Institute of Biological, Environmental and Rural Sciences / Phytoquest Limited, Plas Gogerddan, Aberystwyth, Ceredigion, SY23 3EB, United Kingdom

c Chemistry Research Laboratory, Department of Chemistry, University of Oxford, Oxford, OX1 3TA, United Kingdom

${ }^{d}$ FUSHIMI Pharmaceutical Co. Ltd., 1676 Nakazu-cho, Marugame, Kagawa 763-8605, Japan.

* Corresponding author.

E-mail address: kato@med.u-toyama.ac.jp (A. Kato), george.fleet@sjc.ox.ac.uk (G.W.J. Fleet). 


\section{ABSTRACT :}

Derived from the genus maple (Acer), acertannins are a group of gallotannins which have a characteristic 1,5-anhydro-D-glucitol (1,5-AG) occupying the central core position in the tannic acid structure whose hydroxyl groups have one or more galloyl residues. We synthesized all ten naturallyoccurring acertannins and seven new acertannin derivatives from 1,5-AG. Side-by-side comparison revealed that 2,4,6-trigalloyl-1,5-AG (maplexine E : 21) and maplexine F (2,3,6-trigalloyl-1,5-AG : 22) were good inhibitors of ceramidase (CDase). In contrast, the core anhydrosugar 1,5-AG (12) itself and methoxygallate derivatives (23-25) did not show CDase inhibition. Metabolic labeling experiments using NBD-hexanoic acid revealed that $50 \mu \mathrm{M}$ 6-galloyl-1,5-AG (Ginnalin B : 16), 2,6-digalloyl-1,5AG (Ginnalin A : 19), and 4,6-digalloyl-1,5-AG (4) increased intracellular NBD-labeled ceramide, by 2.3, 2.2, and 2.1-fold, respectively. It is noteworthy that these acertannins $(\mathbf{1 6}, \mathbf{1 9}$, and 4) promoted ceramide synthase 3 (CERS3) gene expression. Acertannins, therefore,represent a new class of potential intracellular ceramide regulators exhibiting both CDase inhibition and ceramide synthase promotion.

Keywords: Acertannins ; 1,5-Anhydro-D-glucitol ; maplexine ; ginnalin ; ceramidase ; ceramide synthase. 


\section{Introduction}

The stratum corneum (SC) is the outermost layer of the skin (thickness 100-300 $\mu \mathrm{m}$ ) and serves as a skin barrier and prevents transepidermal water loss (TEWL) (Coderch et al., 2003), (Mutanu Jungersted et al., 2010), (Meckfessel et al., 2014). Intercellular lipids in SC principally consist of fatty acids, cholesterol, and ceramides; these lipids form characteristic multi-lamellar sheets in intercellular spaces (Kuempel et al., 1998), (Wertz et al., 2000), (Feingold et al., 2014), (Sahle et al., 2015). Previous studies suggested that the ceramide comprised about $50 \%$ of the major lipid species of the SC. This content by percentage is significantly higher than fatty acid (10-20\%), and cholesterol (25\%) (Elias et al., 1991), (Wertz et al., 1998), (Wertz et al., 2006). It is now well recognized that intercellular ceramide level is affected by age, gender, skin type, pigmentation, and life style such as smoking habits etc.

In regard to ceramide biosynthesis, previous studies suggested the existence of a plurality of pathways. Among them, a de novo biosynthetic pathway is mediated by serine palmitoyl-CoA transferase (EC 2.3.1.50) and subsequent ceramide synthase (EC 2.3.1.24) and has essential roles in the control of ceramide levels; ceramide is also supplied by the sphingomyelinase pathway and salvage pathway (Zheng et al., 2006). Ceramide synthases are responsible for the formation of both dihydroceramide and ceramide through $N$-acetylation of dihydrosphingosine and sphingosine (Mullen et al., 2012). The activity of ceramide synthase significantly increases during epidermal differentiation and is clearly higher in keratinocytes and murine epidermis than in most other tissue (Holleran et al., 1990).

On the other hand, in ceramide degradation, ceramidase (CDase ; $N$-acylsphingosine amidohydrolase; EC 3.5.1.23) is a key enzyme in the regulation of ceramide metabolism and catalyzes the degradative $N$ deacylation of ceramide to produce fatty acid and sphingosine. Thereafter, the sphingosine can be converted into sphingosine-1-phosphate through phosphorylation by a sphingosine kinase. Sphingosine1-phosphate acts as a motile second messenger; it regulates various processes such as differentiation, proliferation, and programed cell death, either directly or by serving as a source of signaling metabolites (Spiegel et al., 2002), (Mao et al., 2008), (Maceyka et al., 2012). Many previous reports suggested that 
there is a significant decrease in ceramide levels in the SC of atopic dermatitis patients compared to agematched healthy controls (Imokawa et al., 1991). It is thought that one of the reasons is that the endogenous activities of CDases are gradually increased in proportion by aging, thereby the component amount of skin ceramide tends to decrease. Furthermore, the most commonly expressed reason for this belief was the exogenous ceramidase from colonizing bacteria such as Pseudomonas aeruginosa and Staphylococcus aureus mediate the decrease of ceramide. Thus, CDase inhibitors and/or ceramide synthase activators might have enormous therapeutic potential. [in cosmetics?? Or where??

At present, some compounds mimicking the structures of ceramide or designed "drug-like" compounds have been reported as CDase inhibitors (Figure 1). $N$-Oleoyl-ethanol amine (OEA), a typical ceramidemimicking inhibitor, showed inhibition in keratinocytes (Sugita et al., 1975), (Houben et al., 2007). Some OEA analogues were also synthesized but it was not an effective strategy for improving CDase inhibition (Grijalvo et al., 2006). D-erythro-2-(N-Myristoylamino)-1-phenyl-1-propanol (D-e-MAPP),a lipophilic aromatic ceramide analogue, is a much more potent inhibitor than OAE (Bielawska et al., 1996). This interesting result led to the discovery of the more water soluble $N$-acylphenylaminopropanol-type ceramidase inhibitors such as B13 and LCL-464 (lysosome- and mitochondrium-directed analogues ; LCL-analogues) (Bhabak et al., 2013), (Saied et al., 2014). However, these typical ceramide analogues with long-chain alkyl moieties tend to have poor pharmacological properties due to binding with albumin, resulting in poor bioavailability. Thus, there is a need to identify a new class of small molecule ceramidase inhibitors with more favorable "drug-like" pharmacological properties. To date, three classes of "drug-like" CDase inhibitors have been reported. The quinolinone-based compounds (cerenib-1 and cerenib-2) were screened from a ChemBridge DIVERset library consisting of approximately 50,000 drug-like compounds (Draper et al., 2011). These two compounds inhibit cellular ceramidase activity; in doing so, they reduced cellular sphingosine and S1P. The 5-fluorouracil (5-FU) releasing drug carmofur was found to inhibit intracellular acid CDase activity in vivo (Realini et al., 2013). This effect was independent of the ability to generate 5-FU; 
carmofur also showed synergistic antiproliferative actions with other anticancer drugs (Pizzirani et al., 2013).

In a search for a new class of ceramide level regulator, we turned our attention to plant materials. As part of an ongoing screening program, we found that extracts from the sugar maple (Acer saccharum) and red maple (Acer rubrum L.) and other Acer species had CDase inhibitory effects. The deciduous tree genus Acer is widespread in in eastern and central North America; its tree sap is used for producing maple syrup. Recently,a new gallotannin derivatives “Acertannins” have been identified from these plants and been given the trivial names maplexins and ginnalins ( $\mathrm{Bi}$ et al., 2016). These acertannins varied in the number and location of galloyl groups linked to different positions of a 1,5-anhydro-Dglucitol (1,5-AG) core (Figure 2). They are considered to play a role in protection from predation, and perhaps also serve as pesticides, and in plant growth regulation. Beginning with the discovery of acertannins, in addition to consumption as premium natural sweeteners, the extracts of the Acer genus plants have attracted significant research attention as possible treatments of various disorders including hyperglycemia (Honma et al., 2010), and cancer (González-Sarrías et al., 2012). However, there is limited knowledge of their effects on skin components and their metabolic turnover. We herein describe the synthesis and biological evaluation of a series of acertannins, which includes all 10 naturallyoccurring acertannins (maplexines A-F, ginnalin A-C, 3,6-digalloyl-1,5-anhydro-D-glucitol) (Bock et al., 1980), (Song et al., 1982), (Wan et al., 2012), (Yuan et al., 2012), (Kutani et al., 1960) and seven other acertannin derivatives (Figure 2). An additional aim was to demonstrate the effects of these compounds both on the inhibition of ceramide degradation through ceramidase and the promotion of ceramide production through ceramide synthase.

\section{Results and Discussion}

\subsection{Preparation of maplexines, ginnalins, and acertannins.}


Acertannins were isolated from members of the maple (Acer) genus in concentrations of only 0.0005-0.005 wt.\% (Wan et al., 2012). Reports on previously reported natural acertannins are fragmented and limited; they have been given various names such as maplexine or ginnalin on papers. The synthesis of the central core anhydrosugar 1,5-anhydro-D-glucitol (1,5-AG) has been reported several times: i) Reduction of alkyl glucosides by TESH/Lewis acid (Bennek et al., 1987), (Yuan et al., 2011). ii) Reduction of peracetylated phenyl thioglucoside by Raney-Ni (Ruttens et al., 2007). iii) Reduction of peracetylated $\alpha$-bromoglucoside by $\mathrm{Bu}_{3} \mathrm{SnH}$ under radical conditions (Nie et al., 2005). For the purpose of preparing a series of acertannins, we used the following methods (Scheme 1). Hydrogenation of crude compound (3), which can be prepared by a condensation reaction of 2,3dibenzylated 1,5-AG (1) and 3,4,5-tris-benzyloxy benzoic acid (2), gave 4,6-digalloyl-1,5-AG (4). Highly regioselective cleavage of the 4,6-benzylidene part of (5) was achieved by treatment with sodium cyanoborohydride under acidic conditions. The main product $\mathbf{6 b}$ was converted to 3,4,6-trigalloyl-1,5AG (7) by the same procedure described for the synthesis of (4) from (1). Reaction of 5 with benzyl chloride and sodium hydride afforded the corresponding benzylated compound (8a) and (8b) in 17\% and $41 \%$ yield, respectively. This ratio may be rationalized by steric hindrance of the benzylidene group at the 4,6-position. The ratio of $\mathbf{8 a}$ and $\mathbf{8 b}$ was in contrast to a previous report (Kondo et al., 1977) in which the monobenzoylation of hydroxyl groups of 4,6-benzylidene-1,5-AG (5) gave more of the 3-Obenzyl derivative 8a. 8b was converted to 3,4,6-trigalloyl-1,5-AG (10) by debenzylidenation, followed by the same esterification protocol as in the preparation of (4) in $44 \%$ yield from (8b). 2,3,4,6Tetragalloyl-1,5-AG (11) was prepared from 1,5-AG by the same esterification procedure described for the synthesis of compound (4) in 78\% yield. Other known gallotannins (ginnalin A-C, maplexines A-F, 3,6-digalloyl-1,5-AG) (Bock et al., 1980), (Song et al., 1982), (Wan et al., 2012), (Yuan et al., 2012), (Kutani et al., 1960) were prepared by protection, and galloyl esterification of desired hydroxy groups of 1,5-anhydro-D-glucitol, and finally deprotection. 


\subsection{Inhibitory potency of acertannins for ceramidase (ceramide $N$-deacylase).}

We first compared the ability of acertannins $(4,7,10,11$, and 13-25) to inhibit a ceramidase (ceramide $N$-deacylase) activity (Figure 2), (Table 1). $N$-Oleoyl-ethanol amine (OEA) and carmofur were used as positive controls. The basic core anhydrosugar, 1,5-AG (12) itself exhibited less than $50 \%$ inhibition of ceramidase, even at concentrations as high as $10 \mathrm{mM}$, whereas 2,4,6-trigalloyl-1,5-AG (maplexine E : 21) and 2,3,6-trigalloyl-1,5-AG (maplexine F : 22) were good inhibitors of ceramidase, with IC50 values of 0.8 and $0.7 \mathrm{mM}$, respectively. These activities were slightly weaker than $\mathrm{OAE}$ and carmofur $\left(\mathrm{IC}_{50}=\right.$ 0.11 and $0.18 \mathrm{mM}$, respectively). Thus, we next focused on the galloyl group and whether the number and position could influence the inhibition activities of acertannins. From a comparison of the potency of monogalloyl-1,5-AG (13-16), the galloyl substituent at the C2-position seems most effective because 2-galloyl-1,5-AG (ginnalin $\mathrm{C}$ : 13) had a 3-fold greater $\mathrm{IC}_{50}$ than the other monogalloyl-1,5-AGs. In contrast, the number of gallate groups does not necessarily correspond with inhibition potency, e.g. the newly synthesized 2,3,4,6-tetragalloyl-1,5-AG (11) was five times weaker as an inhibitor than 22. Furthermore, methoxygalloyl-1,5-AGs (23-25) obtained in the present study showed no significant inhibitory activity toward ceramidase. These results suggested that the presence of $\mathrm{OH}$ substituents of galloyl groups linked to a 1,5-AG core is an important factor for the inhibition.

\subsection{Inhibition mechanism of acertannins for ceramidase}

On the basis of these findings, it is clear that the addition of galloyl groups to the 1,5-AG core can lead to the inhibition of ceramidase. However, it has not been completely explained why these acertannins inhibit ceramidase because they do not have a similarity to the ceramide structure. Acertannins are not related to previously reported ceramidase inhibitors (Figure 1). Previous reports of mutational and structural analyses suggested that the mechanism of cleavage of the $N$-acyl linkage of ceramide by ceramidase was similar to that observed for the $\mathrm{Zn}^{2+}$-dependent carboxylpeptidases (Inoue et al., 2009). This reaction starts with the deprotonation of the coordinated water molecule mediated by 
His99 and Arg160; subsequently the resulting hydroxide ion is subjected to nucleophilic attack on the carbonyl carbon atom of ceramide, thereby the amide bond is hydrated. These analytical reports suggested that $\mathrm{Zn}^{2+}$ plays an important role in ceramidase. Furthermore, Inoue et al., compared the threedimensional structures of the active site from bacteria to mammals and found they closely resembled each other by using homology modeling (Inoue et al., 2009). In view of these reports, we envisaged that the inhibition mechanism of acertannins might involve interactions with the zinc ion. To test this hypothesis, we investigated the chelating ability of 1,5-AG (12), 2,3,6-trigalloyl-1,5-AG (maplexine F : 22), 2,4,6-trigalloyl-1,5-AG (maplexine E : 21), 2,3,4,6-tetragalloyl-1,5-AG (11), 2,3,4,6tetramethoxygalloyl-1,5-AG (25), carmofur toward $\mathrm{Zn}^{2+}$ by using eriochrome black $\mathrm{T}$ (EBT) as chelate indicator. Ethylenediaminetetraacetic acid (EDTA) was used as a positive control. The reaction mixture (2 mL) contained $1 \mathrm{mM} \mathrm{ZnCl} 2$ with or without $2 \mathrm{mM}$ samples. A quick color change was observed in the presence of both EDTA and three acertannins (22, 21, and 11) (Figure 3). Thus, it was confirmed that these acertannins have a chelating ability for $\mathrm{Zn}^{2+}$. In sharp contrast, when 1,5-AG (12), 2,3,4,6tetramethoxygalloyl-1,5-AG (25) or carmofur were tested under the same conditions, no change in color was found. These results suggest that 1,5-AG (12) itself does not have chelating ability and the $\mathrm{OH}$ group on the galloyl ring might be interacting with $\mathrm{Zn}^{2+}$. Furthermore, "drug-like" CDase inhibitor carmofur also did not change the color. In order to confirm that the CDase inhibition mechanism was based on chelating with $\mathrm{Zn}^{2+}$, we compared the inhibition activity of these compounds in the presence or absence of satiated [do you mean satiated or saturated ir..??ZnCl 2 . It was found that the activity of ceramidase was clearly lost in the presence of $2 \mathrm{mM}$ EDTA but the activity was restored with $1 \mathrm{mM}$ $\mathrm{ZnCl}_{2}$ (Table 2). These results indicated that the ceramidase activity was controlled by the presence of zinc ions. In contrast, when applied with 2mM 2,3,6-trigalloyl-1,5-AG (maplexine F : 22) and 2,4,6trigalloyl-1,5-AG (maplexine E : 21), the cereamidase activities did not recover. The tannic acids have been used as rust prevention treatment agents for metals for a long time. They react with the metal ions to form metal tannate and thereby forming a coating film whose degree of protection can be controlled 
to some extent by the method of application. This knowledge and our results might suggest that the acertannins (22 and 21) form a chelate but it is different from EDTA with that of acertannins being a more complex and irreversible conjugate interaction with $\mathrm{Zn}^{2+}$.

\subsection{Effect of acertannins on ceramide production through ceramide synthase.}

Dry skin, senile xerosis, is one of the most prevalent dermatological problems seen in the elderly with prevalence rate ranges of 30-58\% (White-Chu et al., 2011), (Hayama et al., 2015). It is caused by disruption of the equilibrium between ceramide synthesis and ceramide degradation cycles and thereby failure of multilamellar sheets in intercellular spaces of SC. Consequently, it causes fissures at the skin surface and decrease of skin barrier function and allows greater transepidermal water loss (TEWL), which also triggers induction of other skin disorders (Takenouchi et al., 1986). A possible strategy for suppressing age-dependent degradation of skin ceramide and preventing transepidermal water loss (TEWL) may be through not only inhibition of ceramidase but also promotion of ceramide synthesis. Epidermal ceramides are generated by i) a de novo pathway involving serine-palmitoyl CoA transferase, ii) ceramide synthase, which catalyze the acylation of sphingosine to form ceramide, iii) sphingomyelin hydrolysis involving sphingomyelinase, and iv) hydrolysis from glucosylsphingolipid involving $\beta$ glucocerebrosidase. We focused on the ceramide synthase pathway. We evaluated acertannins as promoters of ceramide production in vitro in a normal human fibroblast cell line HFb16d by using a metabolic label method. Cells were cultured in the presence of $50 \mu \mathrm{M}$ acertannins $(\mathbf{4}, \mathbf{7}, \mathbf{1 0}, \mathbf{1 1}$, and 1325) and $10 \mu \mathrm{M}$ NBD-hexanoic acid (Matreya LLC., PA, USA) for 24 hrs, and the fluorescence of generated intracellular NBD-ceramide were detected with LAS4000 (Fujifilm, Tokyo, Japan) (Figure 4). The results showed the ratio to non-treated cells. 6-Galloyl-1,5-AG (Ginnalin B : 16), 2,6-digalloyl-1,5AG (Ginnalin A : 19), and 4,6-digalloyl-1,5-AG (4) clearly increased intracellular NBD-labeled ceramide in normal human fibroblast, with increases of 2.3, 2.2, and 2.1-fold, respectively. These three acetannins have a C6-gallate in common, indicating that the gallate group at the C6-position may be a 
factor in promoting potency against ceramide synthase. Furthermore the ceramide production increased dose-dependently (Figure 5). To confirm this promotion effect, we furthermore performed quantitative RT-PCR against ceramide synthase 3 (CERS3), which is highly expressed in keratinocytes (Levy et al., 2010). The relative amount of CERS3 gene was calculated using the $2^{-\Delta \Delta} \mathrm{Ct}$ method with glyceraldehyde 3-phosphate dehydrogenase (GAPDH) as an internal control. 6-galloyl-1,5-AG (Ginnalin B : 16), 2,6digalloyl-1,5-AG (Ginnalin A : 19), and 4,6-digalloyl-1,5-AG (4) clearly increased the expression of CERS3, by 1.5, 1.7, and 1.4-fold, respectively (Figure 6). These results suggested that the increase of internal ceramide production is due to promotion of the expression of ceramide synthase at gene level.

\section{Conclusion}

For the purpose of clarifying the difference in inhibition requirements between the acertannins, we synthesized all 10 naturally-occurring acertannins and synthesized seven new acertannin derivatives and performed side-by-side comparisons. The main features are as follows: (a) 2,4,6-trigalloyl-1,5-AG (maplexine $\mathrm{E}: \mathbf{2 1}$ ) and 2,3,6-trigalloyl-1,5-AG (maplexine F : 22) were good inhibitors of ceramidase, with $\mathrm{IC}_{50}$ values of 0.8 and $0.7 \mathrm{mM}$, respectively. (b) the presence of galloyl groups linked to hydroxyls of the 1,5-AG core is an important factor for the inhibition. (c) acertannins have a chelating ability with $\mathrm{Zn}^{2+}$ which is assumed to be one of the reasons for the CDase inhibition. (d) 6-galloyl-1,5-AG (Ginnalin

B : 16), 2,6-digalloyl-1,5-AG (Ginnalin A : 19), and 4,6-digalloyl-1,5-AG (4) raised intracellular ceramide levels and promoted the CERS3 expression level. Acertannins, therefore, represent a new class of potential intracellular ceramide regulators showing both inhibition of CDase and promotion of ceramide synthase. 


\section{Experimental Section}

\subsection{Chemistry}

Infrared (IR) spectra were recorded on a HORIBA FT-IR spectrometer FT-720. Mass spectra (MS) were recorded on a JEOL JMN-DX 303/JMA-DA 5000 spectrometer. Optical rotations were measured with a JASCO DIP-360, JASCO P-1020 and HORIBA SEPA-300 digital polarimeter. Proton nuclear magnetic resonance (1H NMR) spectra were recorded on a JEOL JNM-AL 300 (300 MHz) spectrometer, using tetramethylsilane as an internal standard. The following abbreviations are used: $\mathrm{s}=$ singlet, $\mathrm{d}=$ doublet, $\mathrm{t}=$ triplet, $\mathrm{q}=$ quartet, $\mathrm{m}=$ multiplet, $\mathrm{br}=$ broad. Column chromatography was carried out on a FUJI SILYSIA CHEMICAL Silica gel PSQ100B (100 mesh) for flash chromatography. Reactions were monitored by TLC (Merck TLC silica gel $60 \mathrm{~F}_{254}$ ) and visualized by charring with Hanessian’s stain.

\subsubsection{4,6-Di-O-galloyl-1,5-anhydro-D-glucitol (4)}

To compound 2 (4.0 g, $8.8 \mathrm{mmol})$ and 1-ethyl-3-(3-dimethylaminopropyl) carbodiimide (EDC) (1.5 g, $9.7 \mathrm{mmol}$ ) in 1,2-dichloroethane (80 mL), compound 4 (Nie et al., 2005) (1.4 g, $4.1 \mathrm{mmol}$ ) was added under Ar. The reaction mixture was allowed to warm to $75{ }^{\circ} \mathrm{C}$ for $12 \mathrm{~h}$. The reaction mixture was poured into $0.1 \mathrm{~N}-\mathrm{HCl}(200 \mathrm{~mL})$, and diluted with $\mathrm{CHCl}_{3}(200 \mathrm{~mL})$. The organic phase was washed with $\mathrm{H}_{2} \mathrm{O}$ (200 mL) and dried $\left(\mathrm{MgSO}_{4}\right)$. Filtration and concentration under reduced pressure gave the crude compound 3 (4.0 g) as a yellow oil. A mixture of unpurified compound 3, 20\% $\mathrm{Pd}(\mathrm{OH})_{2}$ on carbon (100 mg), and 50\% Methanol/THF (80 mL) was treated with hydrogen $\left(0.7 \mathrm{MPa}, 40{ }^{\circ} \mathrm{C}\right)$ for 8 h. Filtration through Celite and purification by silica gel column chromatography (10:1 $\left.\mathrm{CHCl}_{3} / \mathrm{MeOH}\right)$ gave $1.45 \mathrm{~g}$ (76\% from 1) of compound 4 (4,6-digalloyl-1,5-anhydro-D-glucitol) as white solid. $[\alpha]_{\mathrm{D}}{ }^{25}+63.4(c) 1.0$, $\mathrm{MeOH}) ;{ }^{1} \mathrm{H}$ NMR (D $\left.{ }_{2} \mathrm{O}, 300 \mathrm{MHz}\right), \delta 3.62$ - 3.76 (m, 4H), 3.96 (d, 1H, 9.9), 4.08 - 4.24 (m, 2H), 4.94 (t, 1H, 6.6, 7.3), 6.78 (s, 2H), 6.91 (s, 2H); ${ }^{13} \mathrm{C}$ NMR ( $\left.\mathrm{D}_{2} \mathrm{O}, 75 \mathrm{MHz}\right), \delta$ 64.5, 69.8, 69.9, 73.3, 75.5, 
76.0, 110.4, 110.6, 120.5, 138.7, 139.0, 144.9, 145.1, 167.8, 168.1. IR (KBr) 526, 565, 607, 661, 763, 811, 867, 997, 1037, 1099, 1240, 1348, 1452, 1540, 1616, 1700, $3396 \mathrm{~cm}^{-1}$; ESI-TOFMS m/z : calcd for $491.08016\left(\mathrm{M}+\mathrm{Na}^{+}\right)$, found, 491.07917.

\subsubsection{4-O-Benzyl-1,5-anhydro-D-glucitol (6a) and 6-O-Benzyl-1,5-anhydro-D-glucitol (6b)}

The Compound 5 (2.52 g, $10 \mathrm{mmol})$ and $\mathrm{NaCNBH}_{3}(5.02 \mathrm{~g}, 80 \mathrm{mmol})$ were dissolved in THF (50 $\mathrm{mL}$ ) and $\mathrm{HCl}$-gas/1,4-dioxane solution ( ${ }^{\mathrm{ca}} 4 \mathrm{~mol} / \mathrm{L}$ ) was added until the $\mathrm{pH}$ of the solution became 2 3 at $0{ }^{\circ} \mathrm{C}$ under Ar. The mixture was stirred at the same temperature for $18 \mathrm{~h}$. The reaction was quenched by addition of aqueous saturated sodium hydrogen carbonate solution, and concentrated under reduced pressure. The residue was purified by silica gel column chromatography (1:1 Hexane/AcOEt) to give compound 6a (0.14 g, 5.4\%) and $6 \mathbf{b}$ (1.69 g, 65.6\%). 4-O-Benzyl-1,5-anhydro-D-glucitol (6a): $[\alpha]_{\mathrm{D}}^{25}$ +39.7 (c 1.1, MeOH); ${ }^{1} \mathrm{H}$ NMR (CD $\left.\mathrm{CDD}_{3} 300 \mathrm{MHz}\right), \quad \delta 3.14$ (t, 1H, 11.0), 3.21 (ddd, 1H, 2.2, 5.1), 3.27

- 3.31 (overlap, 1H), 3.44 - 3.51 (m, 2H), 3.60 (dd, 1H, 11.8, 5.1), 3.78 (dd, 1H, 11.8, 2.2), 3.89 (dd, 1H, 11.0, 4.9), 4.55 - 4.96 (m, 2H), 7.26 - 7.42 (m, 5H); ${ }^{13} \mathrm{C}$ NMR (CD $\left.{ }_{3} \mathrm{OD}, 75 \mathrm{MHz}\right), \delta$ 62.7, 70.9, 71.8, 75.8, 79.5, 80.4, 81.7, 128.6, 128.9, 129.1, 129.3, 140.0; IR (KBr) 513, 609, 660, 698, 740, 844, 899, 995, 1064, 1114, 1211, 1246, 1330, 1365, 1454, 1496, 2862, 2916, $3035 \mathrm{~cm}^{-1}$; MS (FAB): m/z 255; HRMS (FAB) m/z : calcd for $255.1232\left(\mathrm{M}+\mathrm{H}^{+}\right)$, found, 255.1231. 6-O-Benzyl-1,5-anhydro-D-glucitol (6b) : $[\alpha]_{\mathrm{D}}{ }^{17}+80.7(c$ 0.3, $\mathrm{MeOH}) ;{ }^{1} \mathrm{H} \mathrm{NMR}\left(\mathrm{CDCl}_{3}, 300 \mathrm{MHz}\right), \delta 3.14(\mathrm{t}, 1 \mathrm{H}, 10.6), 3.27$ - 3.33 (m, 1H), 3.40 - 3.42 (m, 2H), 3.53 - 3.62 (m, 1H), 3.64 - 3.70 (m, 2H), 3.91 (dd, 1H, 11.4, 5.5), 4.53 (d, 2H),

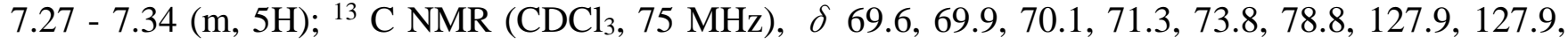
128.5, 137.6 ; IR (KBr) 412, 489, 536, 609, 667, 698, 752, 867, 906, 1010, 1076, 1141, 1211, 1241, 1322, 1369, 1454, 1469, 1650, 1789, 2861, $3351 \mathrm{~cm}^{-1}$; MS (FAB): m/z 254; HRMS (FAB) m/z : calcd for $254.1154(\mathrm{M}+)$ found, 254.1155. 


\subsubsection{2,3,4-Tri-O-galloyl-1,5-anhydro-D-glucitol (7)}

Compound $\mathbf{7}$ was synthesized from compound $\mathbf{6 b}$ according to the same procedure described for the synthesis of compound 4. $[\alpha]_{\mathrm{D}}{ }^{17}-3.2\left(c\right.$ 0.3, MeOH); ${ }^{1} \mathrm{H}$ NMR $\left(\mathrm{CD}_{3} \mathrm{OD}, 300 \mathrm{MHz}\right), \delta 3.49-3.57(\mathrm{~m}$, 2H), 3.62 - 3.70 (m, 2H), 4.24 (dd, 1H, 11.0, 5.5), 5.14 - 5.22 (m, 1H), 5.27 (t, 1H, 9.9), 5.66 (t, 1H,

9.9), 6.87 (s, 2H), 6.93 (s, 2H), 6.93 (s, 2H); ${ }^{13} \mathrm{C}$ NMR (CD3OD, $\left.75 \mathrm{MHz}\right), \delta$ 62.2, 67.9, 70.4, 71.2, 75.4, 80.7, 110.3, 120.4, 120.6, 140.2, 146.3, 146.4, 167.1, 167.2, 167.7; IR (KBr) 764, 868, 995, 1030,

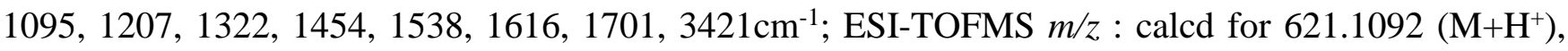
found, 621.1093; MS (FAB): m/z 621; HRMS (FAB) m/z : calcd for 621.1092 (M+), found, 621.1093.

\subsubsection{2-O-Benzyl-4,6-O-benzylidene-1,5-anhydro-D-glucitol (8b) and 3-Benzyl-4,6-benzylidene-}

\section{1,5-anhydro-D-glucitol (8a)}

Compound 5 (2.52 g, $10 \mathrm{mmol}$ ) (Nie et al., 2005) was dissolved in DMF (25 mL) and 60\% $\mathrm{NaH}$ (0.44g, $11 \mathrm{mmol}$ ) was added at $0{ }^{\circ} \mathrm{C}$ under Ar. The mixture was cooled to $-5{ }^{\circ} \mathrm{C}$ and $\mathrm{BnCl}(1.26 \mathrm{~g}, 10$ mmol) was added dropwise over $1 \mathrm{~h}$. The mixture was stirred at the same temperature for $19 \mathrm{~h}$. The reaction was quenched by addition of $\mathrm{MeOH}(10 \mathrm{~mL})$, and diluted with $0.1 \mathrm{~N}-\mathrm{HCl}(200 \mathrm{~mL})$. The products were extracted with AcOEt $(200 \mathrm{~mL})$; the organic phase was washed with water $(200 \mathrm{~mL})$, dried $\left(\mathrm{MgSO}_{4}\right)$, and concentrated under reduced pressure. The residue was purified by silica gel column chromatography (4:1 Hexane/AcOEt) to give compound 8a (1.14 g, 16.8\%) and $\mathbf{8 b}$ (2.76 g, 40.6\%). 3$\boldsymbol{O}$-Benzyl-4,6-O-benzylidene-1,5-anhydro-D-glucitol (8a): $[\alpha]_{\mathrm{D}}{ }^{25}+3.9\left(\right.$ ( $\left.1.0, \mathrm{CHCl}_{3}\right) ;{ }^{1} \mathrm{H} \mathrm{NMR}\left(\mathrm{CDCl}_{3}\right.$, $300 \mathrm{MHz}), \delta 2.36$ (s, 1H), 3.29 - 3.44 (m, 2H), 3.53 - 3.80 (m, 4H), 4.04 (dd, 1H), 4.32 (dd, 1H), 4.88 (dd, 2H), 5.56 (s, 1H), 7.31 - 7.49 (m ,10H); ${ }^{13} \mathrm{C} \mathrm{NMR}\left(\mathrm{CDCl}_{3}, 75 \mathrm{MHz}\right), \delta$ 68.9, 69.9, 70.0, 71.6, 74.7, 82.2, 82.7, 101.3, 126.0, 128.0, 128.1, 128.3, 128.6, 129.0, 137.4, 138.4; IR (KBr) 440, 505, 559, 624, 648, 694, 744, 903, 1003, 1068, 1103, 1138, 1227, 1281, 1365, 1412, 1454, 1496, 1542, 1650, 1809, 2858, 2927, 2978, 3028, $3062 \mathrm{~cm}^{-1}$. MS (FAB): $\mathrm{m} / \mathrm{z}$ 343; HRMS (FAB) $\mathrm{m} / \mathrm{z}$ : calcd for 343.1546 
$\left(\mathrm{M}+\mathrm{H}^{+}\right)$, found, 343.1543. 2-O-Benzyl-4,6-O-benzylidene-1,5-anhydro-D-glucitol (8b): $[\alpha]_{\mathrm{D}}^{25}-28.5$ (c 1.1, $\left.\mathrm{CHCl}_{3}\right) ;{ }^{1} \mathrm{H} \mathrm{NMR}\left(\mathrm{CDCl}_{3}, 300 \mathrm{MHz}\right), \delta 2.68$ (d, 1H), 3.25 - 3.37 (m, 2H), 3.44 (t, 1H, 9.16), 3.52 - 3.67 (m, 2H), 3.83 (ddd, 1H, 9.16, 2.2), 3.99 (dd, 1H, 11.0, 5.9), 4.28 (dd, 1H, 11.0), 4.71 (dd, 2H), 5.49 (s, 1H), 7.23 - 7.50 (m, 5H); ${ }^{13} \mathrm{C}$ NMR (CDCl $\left.3,75 \mathrm{MHz}\right), \delta$ 68.5, 68.8, 71.0, 73.5, 74.9, 77.8, 81.2, 101.9, 126.3, 127.9, 128.0, 128.3, 128.6, 129.2, 137.2, 138.1; IR (KBr) 440, 490, 551, 590, 651, 694, 748, 833, 883, 925, 995, 1041, 1106, 1211, 1265, 1334, 1376, 1450, 1496, 1542, 1589, 1820, 2870,

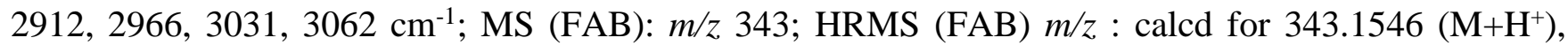
found, 343.1547.

\subsubsection{2-O-Benzyl-1,5-anhydro-D-glucitol (9)}

Compound 8b (900 mg, $2.63 \mathrm{mmol}$ ) was dissolved in $\mathrm{MeOH}(30 \mathrm{~mL})$, and treated with a catalytic amount of $\mathrm{TsOH}$ and the reaction mixture heated to reflux for $12 \mathrm{~h}$. The reaction mixture was neutralized with anion exchange resin, and concentrated under reduced pressure. The residue was purified by silica

gel column chromatography $\left(10: 1 \mathrm{CHCl}_{3} / \mathrm{MeOH}\right)$ to give compound 9 (650 mg, 97\%). $[\alpha]_{\mathrm{D}}^{25}+7.2$ (c 1.0, methanol); ${ }^{1} \mathrm{H}$ NMR (CD $\left.3 \mathrm{OD}, 300 \mathrm{MHz}\right), \delta 3.09$ - 3.17 (m, 2H), 3.22 - 3.47 (m, 3H), 3.59 (dd, 1H, 11.7, 5.9), 3.82 (dd, 1H, 11.7, 2.2), 3.97 (dd, $1 \mathrm{H}, 11.3,5.1), 7.24$ - 7.39 (m, 5H); ${ }^{13} \mathrm{C}$ NMR (CD $\mathrm{OD}, 75$ MHz), $\delta$ 63.1, 68.9, 71.9, 74.1, 79.2, 79.3, 82.3, 128.7, 129.0, 129.3, 140.3; IR (KBr) 439, 489, 551, 590, 651, 694, 748, 833, 883, 925, 995, 1041, 1106, 1157, 1211, 1265, 1334, 1376, 1450, 1496, 1542, 1650, 2869, 2911, 2977, 3031, 3062, $3436 \mathrm{~cm}^{-1}$; MS(EI): m/z: calcd for $254.1154(\mathrm{M}+)$, found, 254.1155.

\subsubsection{3,4,6-Tri-O-galloyl-1,5-anhydro-D-glucitol (10)}

Compound 10 was synthesized from compound $\mathbf{9}$ according to the same procedure described previously for the synthesis of compound 4. $[\alpha]_{\mathrm{D}}{ }^{25}+46.4$ (c 0.2, MeOH); ${ }^{1} \mathrm{H}$ NMR $\left(\mathrm{CD}_{3} \mathrm{OD}, 300 \mathrm{MHz}\right)$, 
$\delta 3.45$ (t, 1H, 11.7, 10.3), 3.88 - 3.96 (m, 2H), 4.09 (dd, 1H, 10.3, 5.5), 4.23 (dd, 1H, 12.4, 4.8), 4.45 (dd, 1H, 12.4, 1.8), 5.29 - 5.41 (m, 2H), 6.95 (s, 2H), 7.00 (s, 2H), 7.08 (s, 2H); ${ }^{13} \mathrm{C}$ NMR (CD 30 D, 75 MHz), $\delta$ 62.5, 68.3, 69.1, 69.7, 76.6, 77.0, 108.9, 109.0, 119.1, 119.8, 138.4, 138.5, 138.8, 144.9, 145.0, 145.1, 165.9, 166.6, 166.7; IR (KBr) 433, 764, 806, 868, 1003, 1033, 1095, 1222, 1319, 1454,

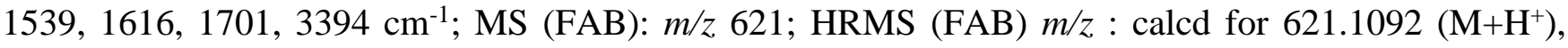
found, 621.1097.

\subsubsection{2,3,4,6-Tetra-O-galloyl-1,5-anhydro-D-glucitol (11)}

Compound 11 was synthesized from 1,5-anhydro-D-glucitol according to the same procedure described previously for compound 4 synthesis. $[\alpha]_{D}{ }^{17}+71.6$ (c 0.2, MeOH); ${ }^{1} \mathrm{H}$ NMR $\left(\mathrm{CD}_{3} \mathrm{OD}, 300\right.$ MHz), $\delta 3.66$ (t, 1H, 11.0), 4.05 (ddd, 1H, 9.9, 2.2), 4.30 - 4.36 (m, 2H), 4,48 (dd, 1H, 12.8, 2.2), 5.29

(m, 1H), 5.51 (t, 1H, 9.9), 5.77 (t, 1H, 9.9), $6.96(\mathrm{~s}, 2 \mathrm{H}), 7.02(\mathrm{~s}, 2 \mathrm{H}), 7.03(\mathrm{~s}, 2 \mathrm{H}), 7.15(\mathrm{~s}, 2 \mathrm{H}) ;{ }^{13} \mathrm{C}$ NMR (CD $\left.{ }_{3} \mathrm{OD}, 75 \mathrm{MHz}\right), \delta$ 63.7, 68.0, 70.3, 71.0, 75.3, 78.0, 110.4, 120.4, 120.4, 120.6, 121.1, 139.9, 140.0, 140.2, 146.2, 146.4, 167.0, 167.2, 167.6, 168.0; IR (KBr) 765, 868, 995, 1030, 1091, 1207, 1323, 1338, 1454, 1539, 1616, 1704, $3386 \mathrm{~cm}^{-1}$. MS (FAB): $\mathrm{m} / \mathrm{z}$ 773; HRMS (FAB) $\mathrm{m} / \mathrm{z}$ : calcd for 773.1201(M+H +), found, 773.1208.

\subsubsection{2,6-Di-O-galloyl-1,5-anhydro-D-glucitol (Ginnalin A : 19) (Bock et al., 1980)}

${ }^{1} \mathrm{H}$ NMR (CD $\left.30 \mathrm{OD}, 300 \mathrm{MHz}\right), \delta 3.26$ - 3.30 (m, 2H, overlap), 3.47 - 3.55 (m, 2H), 3.66 (t, 1H, 8.1, 7.9), 4.05 (dd, 1H, 11.0, 5.0), 4.33 (m, 1H), 4.50 (d, 1H, 11.0), 7.03 (s, 2H), 7.04 (s, 2H); ${ }^{13} \mathrm{C}$ NMR (CD $\left.{ }_{3} \mathrm{OD}, 75 \mathrm{MHz}\right), \delta 64.9,67.9,71.9,73.1,76.9,80.1,110.1,110.2,121.1,121.3,139.8,139.9,146.4$, 146.5, 167.8, 168.3.

\subsubsection{6-O-Galloyl-1,5-anhydro-D-glucitol (Ginnalin B : 16) (Song et al., 1982)}


${ }^{1} \mathrm{H}$ NMR (CD $\left.{ }_{3} \mathrm{OD}, 300 \mathrm{MHz}\right), \delta 3.16$ (t, 1H, 10.3, 11.0), 3.25 - 3.46 (m, 4H), 3.86 (dd, 1H, 11.0, 5.5), 4.27 (dd, 1H, 12.1, 5.5), 4.47 (dd, 1H, 12.1, 1.8), 7.02 (s, 2H); ${ }^{13} \mathrm{C}$ NMR ( $\left.\mathrm{CD}_{3} \mathrm{OD}, 75 \mathrm{MHz}\right), \delta$ 62.7, 71.0, 71.6, 72.8, 77.7, 80.9, 110.3, 121.2, 126.0, 140.0, 146.5, 167.8.

\subsubsection{2-O-Galloyl-1,5-anhydro-D-glucitol (Ginnalin C: 13) (Song et al., 1982)}

${ }^{1} \mathrm{H}$ NMR (CD $\left.3 \mathrm{OD}, 300 \mathrm{MHz}\right), \delta 3.22$ - 3.36 (overlap, m, 4H), 3.57 - 3.64 (m, 2H), 3.84 (d, 1H, 10.6), 4.04 (m, 1H), 7.04 (s, 2H); ${ }^{13} \mathrm{C}$ NMR ( $\left.\mathrm{CD}_{3} \mathrm{OD}, 75 \mathrm{MHz}\right), \delta$ 62.9, 67.8, 72.0, 73.2, 77.0, 82.5, 110.2, 121.1, 139.8, 146.3, 167.7.

\subsubsection{3-O-Galloyl-1,5-anhydro-D-glucitol (Maplexine A : 14) (Wan et al., 2012)}

${ }^{1} \mathrm{H}$ NMR ( $\left.\mathrm{D}_{2} \mathrm{O}, 300 \mathrm{MHz}\right), \delta 3.34-3.44(\mathrm{~m}, 2 \mathrm{H}), 3.62-3.88(\mathrm{~m}, 4 \mathrm{H}), 4.02(\mathrm{~m}, 1 \mathrm{H}) ,5.04(\mathrm{t}, 1 \mathrm{H}$, 10.3, 8.8), 7.20 (s, 2H); ${ }^{13} \mathrm{C}$ NMR ( $\left.\mathrm{D}_{2} \mathrm{O}, 75 \mathrm{MHz}\right), \delta$ 61.7, 68.5, 68.7, 69.4, 80.5, 80.9, 110.9, 121.2, 139.1, 145.3, 168.8 .

\subsubsection{4-O-Galloyl-1,5-anhydro-D-glucitol (Maplexine B : 15) (Wan et al., 2012)}

${ }^{1} \mathrm{H}$ NMR ( $\left.\mathrm{D}_{2} \mathrm{O}, 300 \mathrm{MHz}\right), \delta 3.47$ - 3.70 (m, 6H), 3.98 (dd, 1H, 10.6, 5.1), 4.87 (t, 1H, 9.9, 7.7), 7.13 (s, 2H); ${ }^{13} \mathrm{C}$ NMR $\left(\mathrm{D}_{2} \mathrm{O}, 75 \mathrm{MHz}\right), \delta$ 61.2, 69.6, 70.1, 72.1, 76.2, 79.0, 110.8, 120.8, 139.3, 145.3, 167.9.

\subsubsection{2,3-Di-O-galloyl-1,5-anhydro-D-glucitol (Maplexine C : 17) (Wan et al., 2012)}

${ }^{1} \mathrm{H}$ NMR (CD $\left.3 \mathrm{OD}, 300 \mathrm{MHz}\right), \delta 3.31$ - 3.35 (m, 1H), 3.40 (t, 1H, 10.6), 3.62 - 3.70 (m, 2H), 3.85 (dd, 1H, 11.8, 2.6), 4.15 (dd, $1 \mathrm{H}, 10.6,5.8), 5.02$ (m, 1H), 5.35 (t, 1H, 9.5, 9.2), 6.91 (s, 2H), 7.00 (s, 2H); ${ }^{13}$ C NMR (CD $\left.{ }_{3} \mathrm{OD}, 75 \mathrm{MHz}\right), \delta 62.6,67.8,69.8,71.4,77.9,82.7,110.3,110.3,120.5,121.3,139.9$, 140.1, 146.3, 146.4, 167.4, 168.2. 


\subsubsection{2,4-Di-O-galloyl-1,5-anhydro-D-glucitol (Maplexine D : 18) (Wan et al., 2012)}

${ }^{1} \mathrm{H}$ NMR (CD $\left.3 \mathrm{OD}, 300 \mathrm{MHz}\right), \delta 3.39$ (t, 1H, 10.6), 3.49 - 3.66 (m, 3H), 3.87 (m, 1H), 4.06 (dd, 1H, 10.6, 5.5), 5.14 (t, 1H, 9.2, 9.9), 5.33 (t, 1H, 9.2, 9.5), 6.94 (s, 2H), 6.99 (S, 2H); ${ }^{13} \mathrm{C}$ NMR (CD ${ }_{3} \mathrm{OD}, 75$ $\mathrm{MHz}), \quad \delta$ 62.4, 69.8, 70.6, 71.0, 78.5, 80.6, 110.3, 120.5, 121.2, 139.8, 140.1, 146.3, 146.4, 167.3, 168.1.

\subsubsection{2,4,6-Tri-O-galloyl-1,5-anhydro-D-glucitol (Maplexine E : 21) (Wan et al., 2012)}

${ }^{1} \mathrm{H}$ NMR (CD $\left.{ }_{3} \mathrm{OD}, 300 \mathrm{MHz}\right), 3.41$ (t, 1H, 12.0, 10.6), 3.82 (m, 1H), 3.99 (t, 1H, 9.5, 8.4), 4.11 - 4.19 (m, 2H), 4.37 (dd, 1H, 11.0, 2.6), 5.00 (m, 1H), 5.18 (t, 1H, 9.5), 7.04 (s, 4H), 7.06 (s, 2H); ${ }^{13} \mathrm{C}$ NMR (CD 3 OD, 75 MHz), $\delta$ 64.1, 68.1, 72.6, 73.2, 74.9, 78.3, 110.3, 110.4, 110.5, 121.1, 121.3, 139.9, 140.1, $140.1,146.5,146.5,146.5,167.5,167.7,168.1$.

\subsubsection{2,3,6-Tri-O-galloyl-1,5-anhydro-D-glucitol (Maplexine F : 22) (Yuan et al., 2012)}

${ }^{1} \mathrm{H}$ NMR (CD $\left.\mathrm{OD}, 300 \mathrm{MHz}\right), \delta 3.40$ (t, 1H, 10.6), 3.51 - 3.66 (m, 3H), 3.98 (t, 1H, 9.2), 4.18 (dd, 1H, 11.0, 5.5), 4.95 - 5.04 (m, 2H), 6.90 (s, 1H), 6.95 (s, 1H), 7.03 (s, 2H), 7.05 (s, 2H); ${ }^{13} \mathrm{C}$ NMR (CD $\left.{ }_{3} \mathrm{OD}, 75 \mathrm{MHz}\right), \delta$ 62.7, 68.0, 72.9, 73.4, 75.0, 81.0, 110.4, 110.4, 121.1, 121.2, 140.0, 140.1, 146.5, 146.5, 167.7, 167.7 .

\subsubsection{3,6-Di-O-galloyl-1,5-anhydro-D-glucitol (20) (Kutani et al., 1960)}

${ }^{1} \mathrm{H}$ NMR (CD $\left.\mathrm{OD}, 300 \mathrm{MHz}\right), \delta 3.44$ (dd, 2H), 3.54 - 3.77 (m, 3H), 3.95 (dd, 1H, 11.8, 5.9), 4.34 (dd, 1H, 11.8, 6.9), 4.52 (dd, 1H, 11.8, 1.8), 5.04 (t, 1H, 8.8), 7.03 (s, 2H), 7.09 (s, $2 \mathrm{H}) ;{ }^{13} \mathrm{C}$ NMR (CD $\left.{ }_{3} \mathrm{OD}, 75 \mathrm{MHz}\right), \delta$ 64.9, 69.8, 70.1, 71.1, 80.1, 80.9, 110.1, 110.3, 121.3, 121.8, 139.7, 139.9, 146.4, 
146.5, 168.3, 168.4; IR (KBr) 443, 482, 528, 601, 648, 764, 868, 1038, 1091, 1223, 1315, 1338, 1454, 1539, 1608, 1697, 3629, 3672, $3749 \mathrm{~cm}^{-1}$.

\subsection{Ceramidase inhibition assay}

Ceramidase was isolated and purified from rat brain as described (EI Bawab et al., 1999; Thayyullathil et al., 2011). Briefly, male Wistar rat brains (16 week), obtained from Japan SLC, Inc. (Hamamatsu, Japan) were homogenized in buffer (20 mM phosphate buffer containing 0.25 M sucrose, $1 \mathrm{mM}$ EDTA, and $1 \mathrm{mM}$ AEBSF, pH 7.4) using a Dounce homogenizer. The homogenate was centrifuged at $1000 \times \mathrm{g}$ for $10 \mathrm{~min}$, and the supernatant fractions were thereafter centrifuged at $25,000 \times \mathrm{g}$ for $10 \mathrm{~min}$. The supernatant fractions were furthermore centrifuged at 100,000×g for 60 min and then the pellet was used as a source for ceramidase. All the steps were carried out at $4{ }^{\circ} \mathrm{C}$. For ceramidase activities, the reaction mixture contained $5 \mathrm{mg} / \mathrm{mL}$ rat brain ceramidase in lysis buffer (25 mM Tris/ $\mathrm{HCl}$, pH 8.0, 0.5\% Triton X-100) and $30 \mu \mathrm{M}$ NBD-ceramide (Sigma-Aldrich Co ; St. Louis, Mo, USA), and the incubations were performed for $15 \mathrm{hr}$ at $37{ }^{\circ} \mathrm{C}$ with or without acertannins. The reaction was stopped by adding methanol. The resulting reaction mixture was dried under nitrogen and re-dissolved in $20 \mu \mathrm{L}$ of methanol. The samples were separated on a TLC silica gel-60 plate (Merck Millipore) using chloroform : methanol : 25\% ammonia solution (90: $20: 0.5)$ and their fluorescence were detected with LAS4000 (Fujifilm, Tokyo, Japan). Ceramidase activity was determined by fluorescence of NBDhexanoic acid from NBD-ceramide.

\subsection{Chelating ability test}

The reaction mixture $(2 \mathrm{~mL})$ contained $0.5 \mathrm{mM} \mathrm{ZnCl}_{2}$ in $\mathrm{NH}_{4} \mathrm{Cl}-\mathrm{NH}_{3}$ buffer buffer and Eriochrome black T (EBT) indicator $(10 \mu \mathrm{L})$, and allowed to stand at room temperature with or without $10 \mathrm{mM}$ 
acertannins $(20 \mu \mathrm{L})$. The reversible effect of saturated $\mathrm{ZnCl}_{2}$ on the CDase inhibition was studied by adding $1 \mathrm{mM} \mathrm{ZnCl}_{2}$ with 2mM EDTA or acertannins to the standard CDase assay method.

\subsection{Ceramidase synthase assay}

A human keratinocyte cell line PHK16-0b were cultured with keratinocyte growth medium (Lonza, Basel, Switzerland) in the presence or absence of $50 \mu \mathrm{M}$ acertannins $(4,7,10,11$, and $13-25)$, and then labeled with NBD-hexanoic acid (Sigma-Aldrich Co ; St. Louis, Mo, USA) for 24 hr in a water-jacket incubator at $37^{\circ} \mathrm{C}$ under $5 \% \mathrm{CO}_{2}$. The cells were harvested, washed three times with phosphate-buffered saline and then homogenized for 10 min under sonication. The protein con- centration was determined using a BCA Protein Assay kit (Thermo Fisher Scientific K.K., Kanagawa, Japan) with bovine serum albumin as the standard. NBD-labeled ceramide was extracted by the Bligh \& Dyer extraction method (Bligh et al., 1959). The pooled extracts were dried under nitrogen and re-dissolved in $20 \mu \mathrm{L}$ of methanol. The samples were separated on a TLC silica gel-60 plate (Merck Millipore) using chloroform : methanol : 25\% ammonia solution (90: 20 : 0.5) and their fluorescence was detected with LAS4000 (Fujifilm, Tokyo, Japan).

\subsection{Quantitative RCR analysis}

Total RNAs were isolated from PHK16-0b cells using RNeasy plus mini kit (Qiagen ; Hilden, Germany) according to the manufacturer’s instructions. Quantitative RT-PCR with Mx3000P (Agilent ; Santa Clara, California, USA) was performed by using One step SYBR PrimeScript PLUS RT-PCR kit (Takara-Bio ; Shiga, Japan). The relative amount of target gene was calculated using the $2^{-\Delta \Delta \mathrm{Ct}}$ method with glyceraldehyde 3-phosphate dehydrogenase (GAPDH) as an internal control.

Primers used in PCR reaction are as follows:

CERS3 


$\begin{array}{ll}\text { 5’-TCTTGCAGGTCCTTCACCTT-3’ } & \text { (sense) } \\ \text { 5’-CCTCGTCATCACTCCTCACA-3’ } & \text { (anti-sense) } \\ \text { GAPDH } & \\ \text { 5'-CATGAGAAGTATGACAACAGCCT-3’ } & \text { (sense) } \\ \text { 5'-AGTCCTTCCACGATACCAAAGT-3’ } & \text { (anti-sense) }\end{array}$




\section{Figure Captions}

Figure 1. Structure of known ceramidase inhibitors.

Figure 2. Structure of naturally-occurring acetannins (12-22) and related synthetic acertannin compounds $(4,7,10,11$, and 23-25).

Figure 3. Chelating ability of acertannins (22 and 21) and carmofur against $\mathrm{Zn}^{2+}$. EDTA was used as positive control.

Figure 4. Effect of acertannins $(4,7,10,11$, and 13-25) on ceramide synthesis.

Ceramide synthesis was evaluated by using metabolic label methods with NBD-hexanoic acid.

Figure 5. Dose-dependent effect of acertannins $(\mathbf{1 6}, \mathbf{1 9}$, and $\mathbf{4})$ on ceramide synthesis.

Figure 6. Promotion effect of acertannins $(\mathbf{1 6}, \mathbf{1 9}$, and 4) on expression of ceramide synthase 3 (CERS3) gene

\section{Acknowledgments}

We wish to thank Dr. Ryuta Miyatake (University of Toyama) for technical support of instrumental analysis. 


\section{References and Notes}

1. (a) Coderch, L.; Lopez, O.; de la Maza, A.; Parra, J. L. Am. J. Clin. Dermatol, 2003, 4, 107-129; (b) Mutanu Jungersted, J.; Hellgren, L. I.; Hogh, J. K.; Drachmann, T.; Jemec, G. B.; Agner, T. Acta. Derm. Venereol. 2010, 90, 350-353; (c) Meckfessel, M. H.; Brandt, S. J. Am. Acad. Dermatol, 2014, 71, 177-184.

2. (a) Kuempel, D.; Swartzendruber, D. C.; Squier, C. A.; Wertz, P. W. Biochim. Biophys. Acta. 1998, 1372, 135-140; (b) Wertz, P. W. Acta Derm. Venereol. Suppl. 2000, 208, 7-11 (c) Feingold, K. R.; Elias, P. M. Biochim. Biophys. Acta. 2014, 1841, 280-294; (d) Sahle, F. F.; Gebre-Mariam, T.; Dobner, B.; Wohlrab, J.; Neubert, R. H. Skin Pharmacol. Physiol. 2015, 28, 42-55.

3. (a) Elias, P. M. J. Control Release, 1991, 15, 199-208; (b) Wertz, P. W.; van den Bergh, B. Chem. Phys. Lipids, 1998, 91, 85-96; (c) Wertz, P. W. 2006, In Skin Barrier. P. Elias and K. Feingold, editors. Taylor \& Francis, New York. 33.

4. Zheng, W.; Kollmeyer, J.; Symolon, H.; Momin, A.; Munter, E.; Wang, E.; Kelly, S.; Allegood, J. C.; Liu, Y.; Peng, Q.; Ramaraju, H.; Sullards, M. C.; Cabot, M.; Merrill, A. H., Jr. Biochim. Biophys. Acta. 2006, 1758, 1864-1884.

5. Holleran, W. M.; Williams, M. L.; Gao, W. N.; Elias, P. M. J. Lipid Res. 1990, 31, 1655-1661.

6. Mullen, T. D.; Hannun, Y. A.; Obeid, L. M. Biochem. J. 2012, 441, 789-802.

7. (a) Spiegel, S.; Milstien, S. J. Biol. Chem. 2002, 277, 25851-25854; (b) Mao, C.; Obeid, L. M. Biochim. Biophys. Acta. 2008, 1781, 424-434 (c) Maceyka, M.; Harikumar, K. B.; Milstien, S.; Spiegel, S. Trends Cell Biol. 2012, 22, 50-60.

8. Imokawa, G. J. Dermatol. Sci. 2009, 55, 1-9. 
9. (a) Sugita, M.; Willians, M.; Dulaney, J. T.; Moser, H. W. Biochim. Biophys. Acta. 1975, 398, $125-$ 131; (b) Houben, E.; Uchida, Y.; Nieuwenhuizen, W. F.; De Paepe, K.; Vanhaecke, T.; Holleran, W. M.; Rogiers, V. Skin Pharmacol Physiol., 2007, 20, 187-194.

10. Grijalvo, S.; Bedia, C.; Triola, G.; Casas, J.; Llebaria, A.; Teixidó, J.; Rabal, O.; Levade, T.; Delgado, A.; Fabriàs, G. Chem Phys Lipids. 2006, 144, 69-84.

11. Bielawska, A.; Greenberg, M. S.; Perry, D.; Jayadev, S.; Shayman, J. A.; McKay, C.; Hannun, Y. A. J. Biol. Chem. 1996, 271, 12646-54.

12. (a) Bhabak, K. P.; Kleuser, B.; Huwiler, A.; Arenz, C. Bioorg. Med. Chem. 2013, 21, 874-82; (b) Saied, E. M.; Arenz, C. Cell Physiol. Biochem. 2014, 34, 197-212.

13. Draper, J. M.; Xia, Z.; Smith, R. A.; Zhuang, Y.; Wang, W.; Smith, C. D. Mol. Cancer Ther. 2011, 10, 2052-2061.

14. Realini, N.; Solorzano, C.; Pagliuca, C.; Pizzirani, D.; Armirotti, A.; Luciani, R.; Costi, M. P.; Bandiera, T.; Piomelli, D. Sci. Rep. 2013, 3, 1035.

15. Pizzirani, D.; Pagliuca, C.; Realini, N.; Branduardi, D.; Bottegoni, G.; Mor, M.; Bertozzi, F.; Scarpelli, R.; Piomelli, D.; Bandiera, T. J. Med. Chem. 2013, 56, 3518-3530.

16. Bi, W.; Gao, Y.; Shen, J.; He, C.; Liu, H.; Peng, Y.; Zhang, C.; Xiao, P. J. Ethnopharmacol. 2016, 189, 31-60.

17. Honma, A.; Koyama, T.; Yazawa, K. J. Enzyme Inhib. Med. Chem. 2011, 26, 176-180.

18. Gonzalez-Sarrias, A.; Yuan, T.; Seeram, N. P. Food Chem. Toxicol. 2012, 50, 1369-1376.

19. Wan, C.; Yuan, T.; Li, L.; Kandhi, V.; Cech, N. B.; Xie, M.; Seeram, N. P. Bioorg Med Chem Lett. 2012, 22, 597-600.

20. (a) Bennek, J. A.; Gray, G. R. J. Org. Chem., 1987, 52, 892-897; (b) Yuan, C.; Hollingsworth, R. I. Tetrahedron Lett., 2011, 52, 5421-5423; (c) Ruttens, B.; Blom, P.; van Hoof, S.; Hubrecht, I.; 
van der Eycken, J.; Sas, B.; van hemel, J.; Vandenkerckhove, J. J. Org. Chem., 2007, 72, 55145522; (d) Nie, X.; Wang, G. J. Org. Chem., 2005, 70, 8687-8692.

21. Kondo, Y. Agric. Biol. Chem., 1977, 41, 2481-2482.

22. (a) Bock, K.; laCour, N. F. Jensen, S. R.; Nielsen, B. J. Phytochemistry, 1980, 19, 2033; (b) Song, C.-Q; Zhang, N.; Xu, R.-S; Song, G.-Q; Sheng, Y. Acta Chim. Sinica 1982, 40, 1142-1147; (c) Yuan, T.; Wan, C.; Liu, K.; Seeram, N. P. Tetrahedron, 2012, 68, 959-964; (d) Kutani, N. Chem. Pharm. Bull. 1960, 8, 72-76.

23. Realini, N.; Solorzano, C.; Pagliuca, C.; Pizzirani, D.; Armirotti, A.; Luciani, R.; Costi, M. P.; Bandiera, T.; Piomelli, D. Sci. Rep. 2013, 3, 1035.

24. Inoue, T.; Okino, N.; Kakuta, Y.; Hijikata, A.; Okano, H.; Goda, H. M.; Tani, M.; Sueyoshi, N.; Kambayashi, K.; Matsumura, H.; Kai,Y.; Ito, M. J. Biol. Chem. 2009, 284, 9566-9577.

25. (a) White-Chu, E. F.; Reddy, M. Clin. Dermatol. 2011, 29, 37-42; (b) Hayama, K.; Takano, Y.; Tamura, J.; Tagami, H.; Terui, T. Australas J. Dermatol. 2015, 56, 36-39.

26. Takenouchi, M.; Suzuki, H.; Tagami, H. J. Invest. Dermatol. 1986, 87, 574-576.

27. Levy, M.; Futerman, A. H. IUBMB Life. 2010, 62, 347-356.

28. El Bawab, S.; Bielawska, A.; Hannun, Y. A. J. Biol. Chem. 1999, 274, 39, 27948-27955.

29. Thayyullathil, F.; Chathoth, S.; Hago, A.; Patel, M.; Szulc, Z. M.; Hannun, Y.; Galadari, S. Biochim. Biophys. Acta., 2011, 1811, 242-252.

30. Bligh, E. G.; Dyer, W. J. Can. J. Biochem. Physiol. 1959, 37, 911-917. 
Table 1. Concentration of red maple components giving and related synthtic compounds $50 \%$ inhibition of ceramidase.

\begin{tabular}{|c|c|}
\hline \multicolumn{2}{|l|}{$\mathrm{IC}_{50}(\mathrm{mM})$} \\
\hline Compound & Ceramidase \\
\hline \multicolumn{2}{|l|}{ Anhydrosugar } \\
\hline 1,5-Anhydro-D-glucitol $(1,5-A G: 12)$ & ${ }^{\mathrm{a}} \mathrm{NI}$ \\
\hline \multicolumn{2}{|l|}{ Monogalloyl-1,5-AG } \\
\hline 2-Galloyl-1,5-AG (Ginnalin C : 13) & $1.0 \pm 0.1$ \\
\hline 3-Galloyl-1,5-AG (Maplexine A : 14) & $3.0 \pm 0.4$ \\
\hline 4-Galloyl-1,5-AG (Maplexine B : 15) & $2.3 \pm 0.2$ \\
\hline 6-Galloyl-1,5-AG (Ginnalin B : 16) & $3.5 \pm 0.5$ \\
\hline \multicolumn{2}{|l|}{ Digalloyl-1,5-AG } \\
\hline 2,3-Digalloyl-1,5-AG (Maplexine C : 17) & $1.2 \pm 0.1$ \\
\hline 2,4-Digalloyl-1,5-AG (Maplexine D : 18) & $1.0 \pm 0.2$ \\
\hline 2,6-Digalloyl-1,5-AG (Ginnalin A : 19) & $1.6 \pm 0.1$ \\
\hline 3,6-Digalloyl-1,5-AG (20) & $1.3 \pm 0.1$ \\
\hline 4,6-Digalloyl-1,5-AG (4) & $2.0 \pm 0.04$ \\
\hline \multicolumn{2}{|l|}{ Trigalloyl-1,5-AG } \\
\hline 2,4,6-Trigalloyl-1,5-AG (Maplexine E : 21) & $0.8 \pm 0.1$ \\
\hline 2,3,6-Trigalloyl-1,5-AG (Maplexine F : 22) & $0.7 \pm 0.03$ \\
\hline 2,3,4-Trigalloyl-1,5-AG (7) & $1.3 \pm 0.1$ \\
\hline 3,4,6-Trigalloyl-1,5-AG (10) & $1.3 \pm 0.2$ \\
\hline \multicolumn{2}{|l|}{ Tetragalloyl-1,5-AG } \\
\hline 2,3,4,6-Tetragalloyl-1,5-AG (11) & $3.7 \pm 0.3$ \\
\hline \multicolumn{2}{|l|}{ Methoxygalloyl-1,5-AG } \\
\hline 6-Methoxygalloyl-1,5-AG (23) & NI \\
\hline 4,6-Dimethoxygalloyl-1,5-AG (24) & NI \\
\hline 2,3,4,6-Tetramethoxygalloyl-1,5-AG (25) & NI \\
\hline \multicolumn{2}{|l|}{ Positive control } \\
\hline$N$-Oleoyl-ethanol amine (OEA) & $0.17 \pm 0.01$ \\
\hline Carmofur & $0.11 \pm 0.02$ \\
\hline
\end{tabular}

${ }^{a}$ Less than $50 \%$ inhibition at $10 \mathrm{mM}$. 
Table 2. Effects of $\mathrm{ZnCl}_{2}$ on the inhibitory activity of $2 \mathrm{mM}$ EDTA and acertannins (22 and 21) on ceramidase.

\begin{tabular}{lcc}
\hline \multirow{2}{*}{ Compound } & \multicolumn{2}{c}{ Inhibition of activity (\%) } \\
\cline { 2 - 3 } & without & with $\mathrm{ZnCl}_{2}(\mathrm{mM})$ \\
\hline \hline EDTA & $76.2 \pm 1.8$ & $27.3 \pm 4.0$ \\
2,3,6-Trigalloyl-1,5-AG (Maplexine $\mathrm{F}: 22)$ & $73.6 \pm 3.5$ & $74.4 \pm 1.8$ \\
2,4,6-Trigalloyl-1,5- $\mathrm{AG}$ (Maplexine $\mathrm{E}: \mathbf{2 1})$ & $62.3 \pm 2.7$ & $67.2 \pm 1.7$
\end{tabular}




\section{Scheme 1}

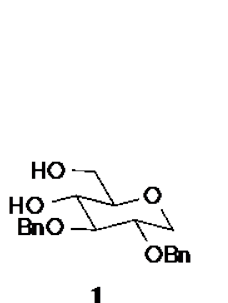

1
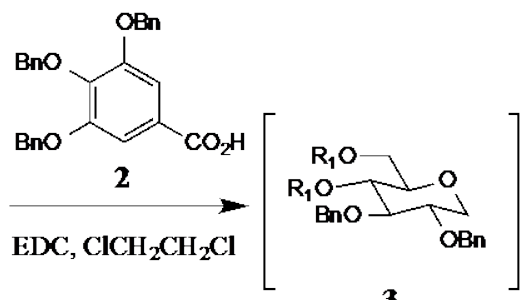

3

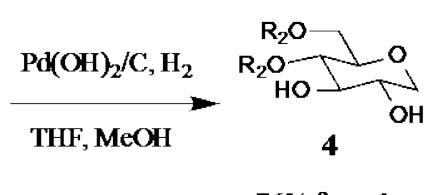

$76 \%$ from 1

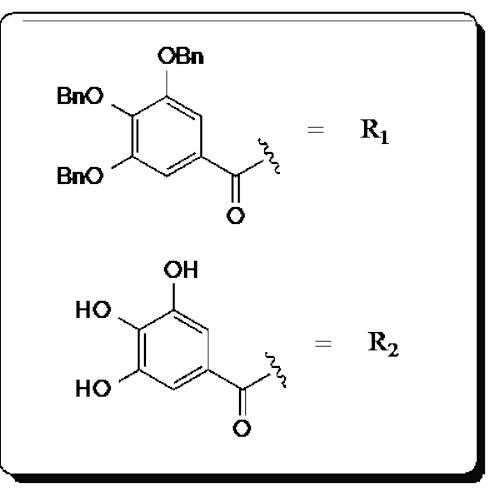

1) $\mathrm{EDC}, 2$

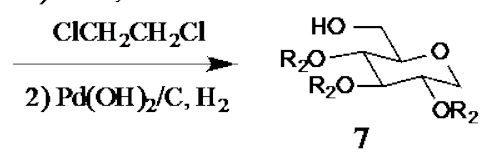

$92 \%$ from 6
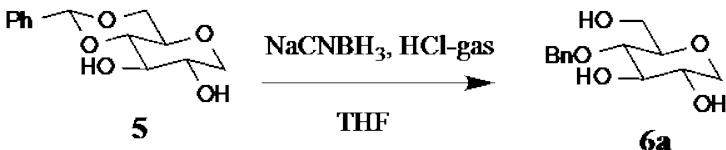

$5 \%$

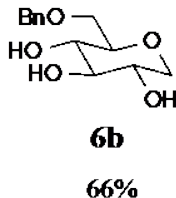

$66 \%$
1) EDC, 2

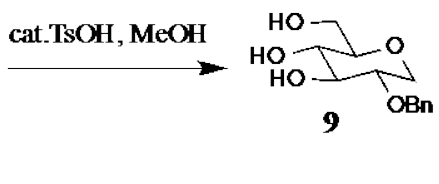

$\mathrm{ClCH}_{2} \mathrm{CH}_{2}$

2) $\mathrm{Pd}(\mathrm{OH})_{2} / \mathrm{C}, \mathrm{H}_{2}$ 8b

$41 \%$

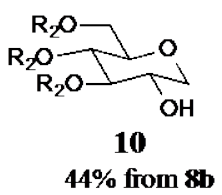


Figure 1

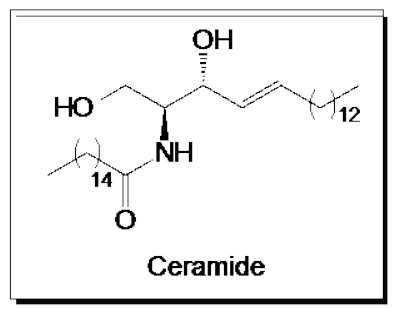

i) endocannabinoid-related compound

ii) lipophilic aromatic ceramide analogue

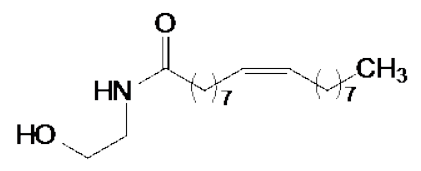

N-oleoylethanolamine

(OEA)

iii) quinolinone-based compounds

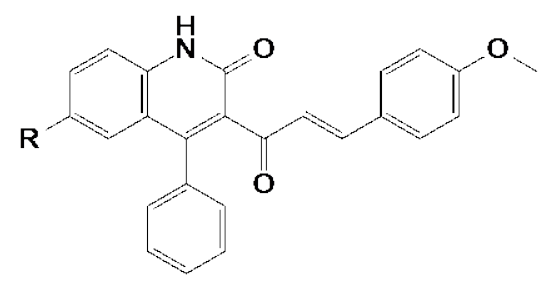

Ceranib-1: $\mathrm{R}=\mathrm{Me}$

Ceranib-2: $\mathrm{R}=\mathrm{H}$
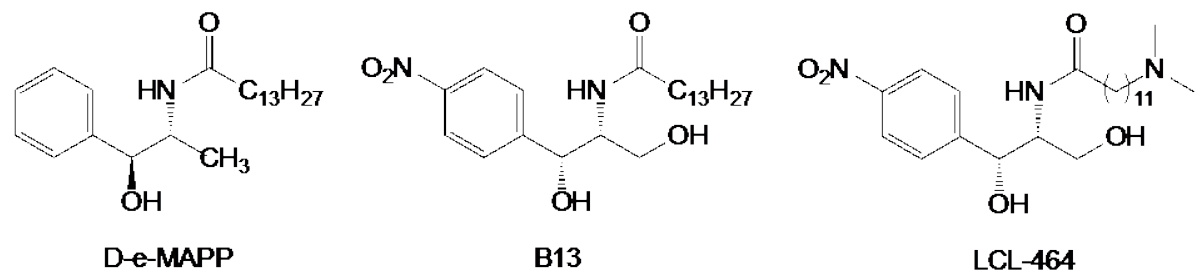

iv) 2,4-dioxopyrimidine-1-carboxamide derivatives

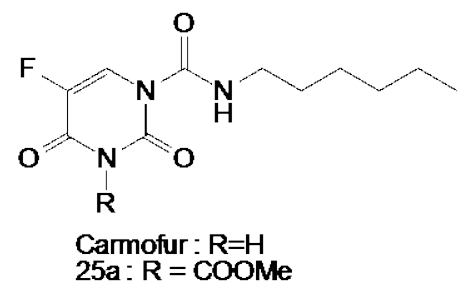


Figure 2

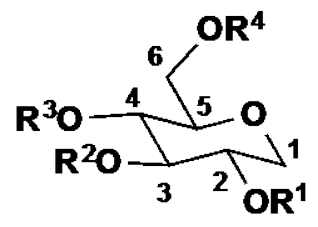

12: $\mathrm{R}^{1}=\mathrm{R}^{2}=\mathrm{R}^{3}=\mathrm{R}^{4}=\mathrm{H}$

13: $\mathrm{R}^{1}=$ Galloyl, $\mathrm{R}^{2}=\mathrm{R}^{3}=\mathrm{R}^{4}=\mathrm{H}$

14: $R^{2}=$ Galloyl, $R^{1}=R^{3}=R^{4}=H$

15: $\mathrm{R}^{3}=$ Galloyl, $\mathrm{R}^{1}=\mathrm{R}^{2}=\mathrm{R}^{4}=\mathrm{H}$

16: $\mathrm{R}^{4}=$ Galloyl, $\mathrm{R}^{1}=\mathrm{R}^{2}=\mathrm{R}^{3}=\mathrm{H}$

17: $\mathbf{R}^{1}=\mathbf{R}^{2}=$ Galloyl, $\mathbf{R}^{3}=\mathbf{R}^{4}=\mathbf{H}$

18: $R^{1}=R^{3}=$ Galloyl, $R^{2}=R^{4}=H$

19: $\mathbf{R}^{1}=\mathbf{R}^{4}=$ Galloyl, $\mathbf{R}^{2}=\mathrm{R}^{3}=\mathrm{H}$

20: $\mathbf{R}^{2}=\mathbf{R}^{4}=$ Galloyl, $\mathbf{R}^{1}=\mathbf{R}^{3}=\mathbf{H}$

4: $\mathrm{R}^{3}=\mathrm{R}^{4}=$ Galloyl, $\mathrm{R}^{1}=\mathrm{R}^{2}=\mathrm{H}$

21: $\mathbf{R}^{1}=\mathbf{R}^{3}=\mathbf{R}^{4}=$ Galloyl, $\mathbf{R}^{2}=\mathbf{H}$

22: $\mathbf{R}^{1}=\mathbf{R}^{2}=\mathbf{R}^{4}=$ Galloyl, $\mathbf{R}^{3}=\mathbf{H}$

7: $\mathrm{R}^{1}=\mathrm{R}^{2}=\mathrm{R}^{3}=$ Galloyl, $\mathrm{R}^{\mathbf{4}}=\mathbf{H}$

10: $R^{2}=R^{3}=R^{4}=$ Galloyl, $R^{1}=H$

11: $\mathrm{R}^{1}=\mathrm{R}^{2}=\mathrm{R}^{3}=\mathrm{R}^{4}=$ galloyl

$23: \mathrm{R}^{4}=3^{\prime}, 4^{\prime}, 5^{\prime}$-trimethoxy benzoyl, $\mathrm{R}^{1}=\mathrm{R}^{2}=\mathrm{R}^{3}=\mathrm{H}$

24: $\mathrm{R}^{3}=\mathrm{R}^{4}=3^{1}, 4^{\prime}, 5^{\prime}$-trimethoxy benzoyl, $\mathrm{R}^{1}=\mathrm{R}^{2}=\mathrm{H}$

25: $\mathrm{R}^{1}=\mathrm{R}^{2}=\mathrm{R}^{3}=\mathrm{R}^{4}=3^{\prime}, 4^{\prime}, 5^{\prime}$-trimethoxy benzoyl 
Figure 3

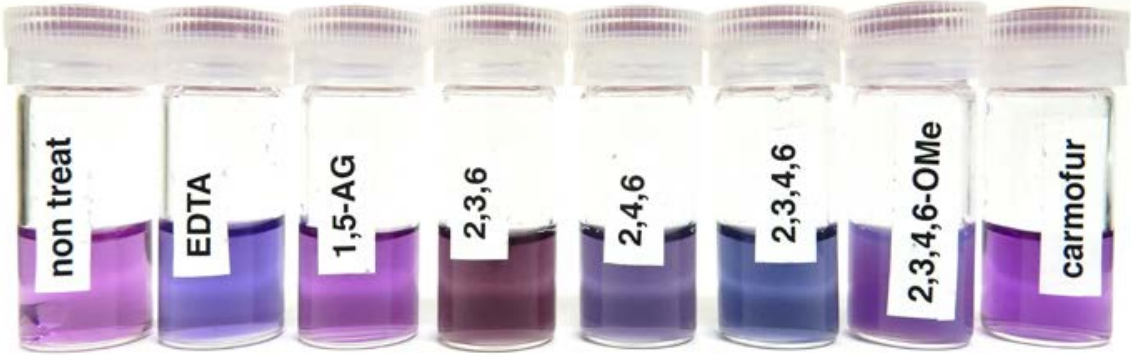


Figure 4

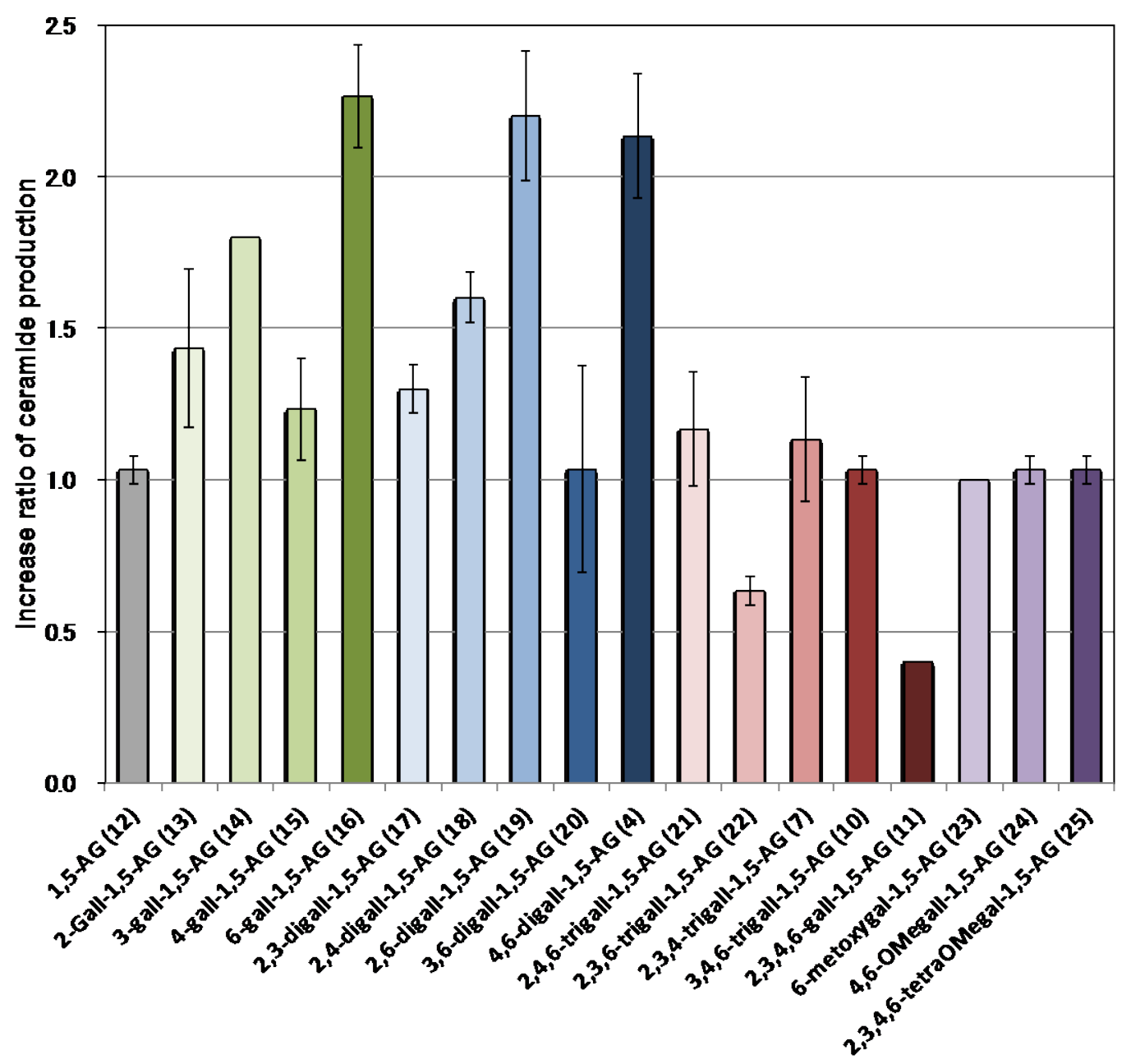


Figure 5

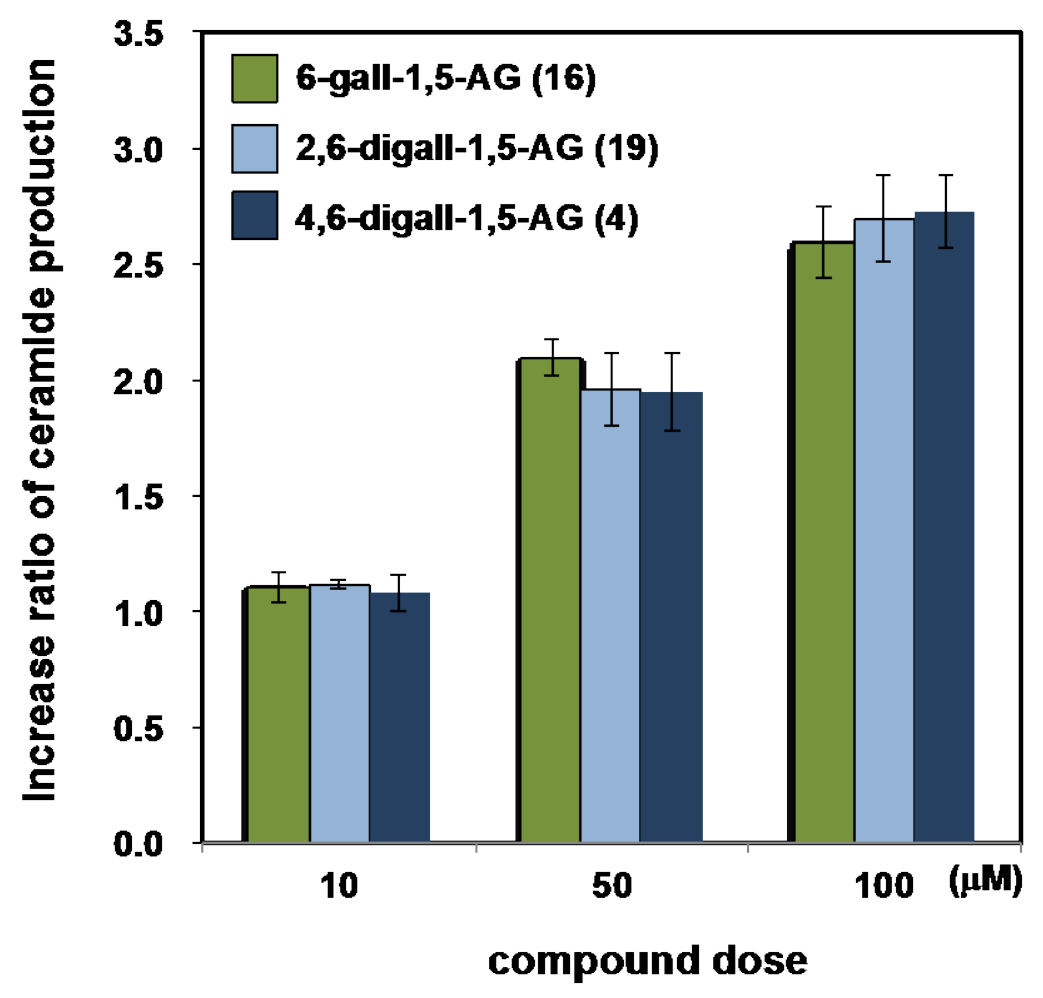


Figure 6

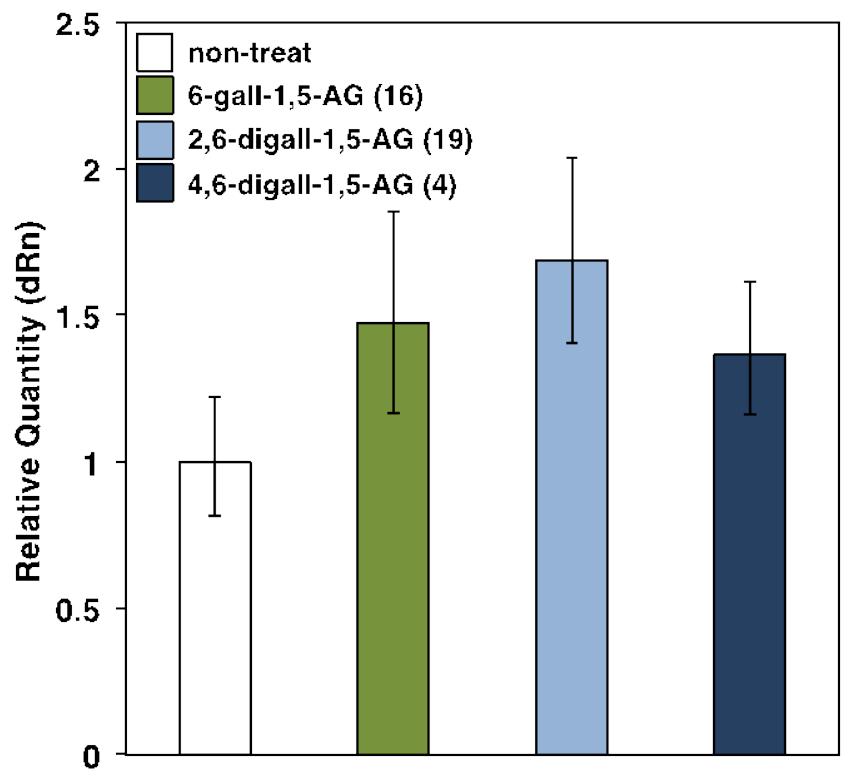

